\title{
Medicine possession ratio as proxy for adherence to antiepileptic drugs: prevalence, associations, and cost implications
}

This article was published in the following Dove Press journal:

Patient Preference and Adherence

12 April 2016

Number of times this article has been viewed

\author{
Karen Jacobs' \\ Marlene Julyan ${ }^{2}$ \\ Martie S Lubbe' \\ Johanita R Burger' \\ Marike Cockeran' \\ 'Medicine Usage in South Africa, \\ Faculty of Health Sciences, ${ }^{2}$ Clinical \\ Pharmacy, School of Pharmacy, \\ North-West University \\ (Potchefstroom Campus), \\ Potchefstroom, South Africa
}

Objective: To determine the adherence status to antiepileptic drugs (AEDs) among epilepsy patients; to observe the association between adherence status and age, sex, active ingredient prescribed, treatment period, and number of comorbidities; and to determine the effect of nonadherence on direct medicine treatment cost of AEDs.

Methods: A retrospective study analyzing medicine claims data obtained from a South African pharmaceutical benefit management company was performed. Patients of all ages $(N=19,168)$, who received more than one prescription for an AED, were observed from 2008 to 2013. The modified medicine possession ratio (MPRm) was used as proxy to determine the adherence status to AED treatment. The MPRm was considered acceptable (adherent) if the calculated value was $\geq 80 \%$, but $\leq 110 \%$, whereas an MPRm of $<80 \%$ (unacceptably low) or $>110 \%$ (unacceptably high) was considered nonadherent. Direct medicine treatment cost was calculated by summing the medical scheme contribution and patient co-payment associated with each AED prescription.

Results: Only 55\% of AEDs prescribed to 19,168 patients during the study period had an acceptable MPRm. MPRm categories depended on the treatment period $(P>0.0001$; Cramer's $V=0.208)$ but were independent of sex $(P<0.182$; Cramer's $V=0.009)$. Age group $(P<0.0001$; Cramer's $V=0.067)$, active ingredient $(P<0.0001$; Cramer's $V=0.071)$, and number of comorbidities $(P<0.0001$; Cramer's $V=0.050)$ were statistically but not practically significantly associated with MPRm categories. AEDs with an unacceptably high MPRm contributed to $3.74 \%$ (US\$736,376.23) of the total direct cost of all AEDs included in the study, whereas those with an unacceptably low MPRm amounted to US\$3,227,894.85 (16.38\%).

Conclusion: Nonadherence to antiepileptic treatment is a major problem, encompassing $\sim 20 \%$ of cost in our study. Adherence, however, is likely to improve with the treatment period. Further research is needed to determine the factors influencing epileptic patients' prescription refill adherence.

Keywords: adherence, medicine possession ratio, medical costs, treatment period, antiepileptic drugs

\section{Introduction}

Approximately 50 million people globally suffer from epilepsy, of whom $~ 85 \%$ live in developing countries. ${ }^{1}$ According to the World Health Organization, the annual incidence in developed countries is $\sim 50$ per 100,000 of the general population, whereas in developing countries the incidence is nearly 100 per $100,000 .^{1}$ The most recent prevalence studies conducted in South Africa in 2000 and 2014 reported a lifetime prevalence of 7.3/1,000 in children of a rural district and a crude adjusted prevalence of 7.0/1,000 in children of a rural northeast district. ${ }^{2,3}$
Correspondence: Johanita R Burger Medicine Usage in South Africa (MUSA), Faculty of Health Sciences, North-West University, Potchefstroom Campus,

Private Bag x600I, Potchefstroom, 2520 South Africa

Tel +27 I8 2992285

Email johanita.burger@nwu.ac.za (c) (1) (5) 2016 Jacobs et al. This work is published and licensed by Dove Medical Press Limited. The full terms of this license are available at https://www.dovepress.com/terms.php cc) ${ }_{\mathrm{BY}} \mathrm{NC}$ and incorporate the Creative Commons Attribution - Non Commercial (unported, v3.0) License (http://creativecommons.org/licenses/by-nc/3.0/). By accessing the work you hereby accept the Terms. Non-commercial uses of the work are permitted without any further permission from Dove Medical Press Limited, provided the work is properly attributed. For permission for commercial use of this work, please see paragraphs 4.2 and 5 of our Terms (https://www.dovepress.com/terms.php). 
Epilepsy has a major impact on the general health of patients and influences the quality of life, performance at work and school, and everyday social life. ${ }^{4}$ Furthermore, epilepsy carries an increased risk for seizure-related injuries and mortality compared with the general population..$^{5-8}$

Although antiepileptic drug (AED) therapy does not offer a permanent cure to epilepsy, successful therapy can eliminate or reduce symptoms. Adherence to AEDs (defined as the extent to which patients are able to follow the recommendations for prescribed treatments) is subsequently a key to treatment success.

Nonadherence with medication is a complex problem that has many determinants. According to the World Health Organization, ${ }^{9}$ the factors affecting adherence can be grouped into the following five dimensions: socioeconomic-related factors, health care team/health system-related factors, condition-related factors, treatment-related factors, and patient-related factors. Patients may be nonadherent at any time during their treatment, ${ }^{10} \mathrm{eg}$, they may use more or less than the prescribed treatment or discontinue treatment prematurely. ${ }^{11}$ Insufficient monthly supply (undersupply) of medication leads to inadequate treatment with subsequent uncontrolled seizures and poor quality of life, ${ }^{12-18}$ morbidity, and mortality, ${ }^{19,20}$ whereas the oversupply of medication may lead to potential toxicities ${ }^{21}$ and increased health care costs ${ }^{22-27}$ or wasted resources. ${ }^{28}$ Both undersupply and oversupply of medicine are considered to be forms of nonadherence. ${ }^{23,29}$ The prevalence of nonadherence to AEDs in patients with epilepsy generally tend to be high, ${ }^{9}$ ranging from $20 \%$ to $80 \%{ }^{13,15,30-34}$ depending on the populations studied, definition used for nonadherence, and research methods. ${ }^{35}$ The assessment of adherence should be a routine action in the management of epilepsy - not only to improve patients' health, but also as a cost-saving initiative.

There is paucity of information on the prevalence and economic consequences of nonadherence in South Africa. The aim of this study was 1) to determine the adherence status to AEDs among epilepsy patients in the private health sector of South Africa and observe whether there is an association between the adherence status (modified medicine possession ratio [MPRm] categories) and age, sex, active ingredient prescribed, treatment period, and number of comorbidities, and 2) to determine the effect of nonadherence on the direct medicine treatment cost of AEDs.

\section{Methods}

\section{Patients and study design}

We conducted a retrospective, longitudinal study analyzing medicine claims data obtained from a South African pharmaceutical benefit management company. Continuously enrolled patients of all ages, who were prescribed one or more AEDs over a 6-year period from January 1, 2008 to December 31, 2013, were eligible for the analysis.

We extracted data regarding patient demographics (sex and date of birth) and pertinent prescription information (such as drug trade name, days supplied, dispensing date, quantity of medicine prescribed, and the Tenth Revision of the International Classification of Diseases [ICD-10] code per claim). The quality of the data was ascertained by means of several automated validation processes applied by the pharmaceutical benefit management company, such as data integrity validation and eligibility management.

This study was approved by the Health Research Ethics Committee of the North-West University (NWU-0017914-A1). Permission for the use of the data was granted by the board of directors of the pharmaceutical benefit management company. The data were analyzed anonymously. Privacy and confidentiality of the data were maintained at all times, and therefore no patient or medical scheme could be traced.

\section{Inclusion criteria}

Patients were included in the study if they 1) had a recorded diagnosis of epilepsy (ICD-10 code G40) during the study period in conjunction with a paid claim reimbursed through the prescribed minimum benefit (PMB) as part of the chronic disease list (CDL) for antiepileptic medicine; and 2) filled a prescription for single or multiple AEDs more than once during the study period (Figure 1).

\section{Study population}

A total of 45,250,902 prescriptions were analyzed. The study population was narrowed down to 20,210 patients receiving antiepileptic medication (defined as drugs from the Anatomical Therapeutic Chemical classification group: N03AA, N03AB, N03AE, N03AD, N03AF, N03AG, and N03AX) during the study period, by applying the inclusion criteria. Of these patients, 19,168 patients received more than one prescription for an AED over the study period (Figure 1).

\section{Adherence measure}

The MPRm measure was used as a proxy to determine adherence. The MPRm is an adherence percentage value that is an internationally accepted and well-documented method to calculate drug adherence in pharmacoepidemiological studies and chronic diseases. ${ }^{36-39}$ The MPRm measure is calculated from the medicine claims data by using the following formula: ${ }^{40}$

$$
\text { MPRm }=\frac{\text { Total days supplied }}{\text { Last claim date }- \text { first claim date }+ \text { days supplied }} \times 100
$$




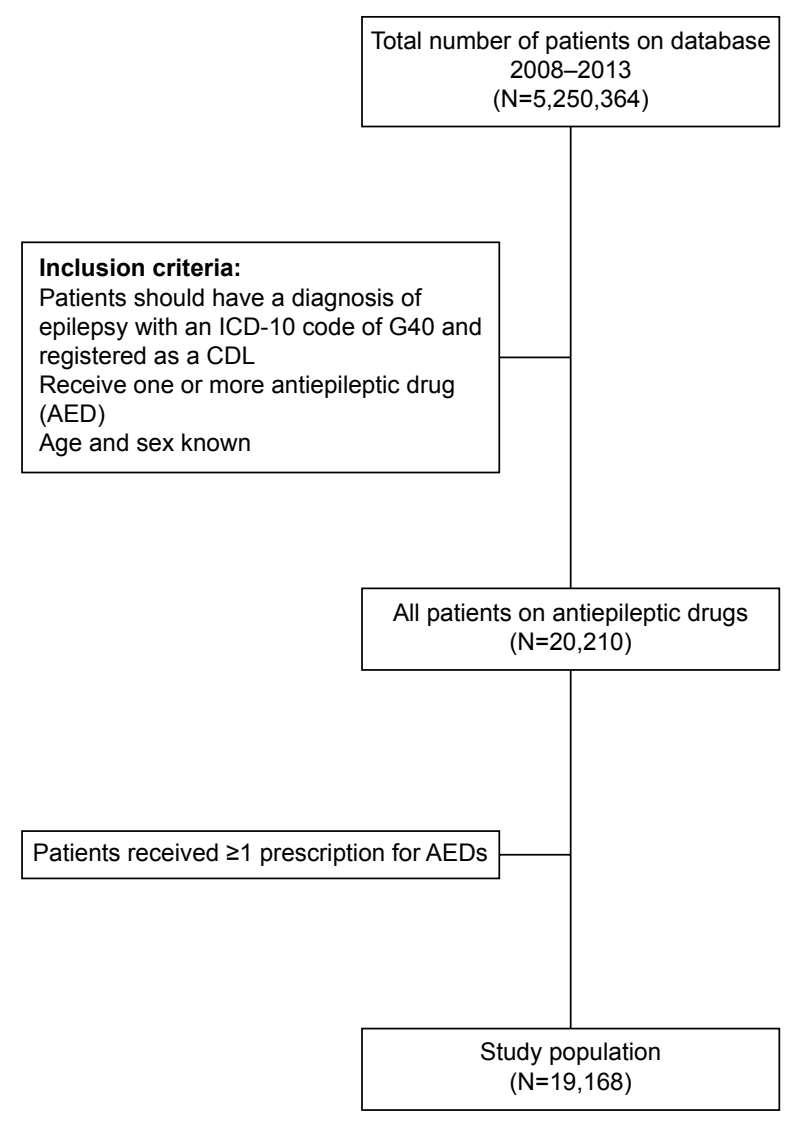

Figure I Study population selection.

Abbreviations: ICD-I0, the Tenth Revision of the International Classification of Diseases; CDL, chronic disease list.

Adherence measures based on the MPRm provide an indication of the possession of the medicine by the patient; however, the consumption of the medication by the patient can only be assumed to follow from the possession. ${ }^{41}$ On the basis of pharmacy refill data, patients with medications available $80 \%$ of the time have generally been categorized as adherent in the literature. ${ }^{25,42}$ The MPRm was thus considered acceptable if the calculated value is $\geq 80 \%$, but $\leq 110 \%$. An MPRm of less than $80 \%$ indicates undersupply of medication or the presence of refill gaps, so that possession is considered unacceptably low and nonadherent, whereas an MPRm greater than $110 \%$ (oversupply) was deemed unacceptably high and thus also nonadherent. Oversupply represents possible waste and exhaustion of resources, whereas undersupply represents opportunity cost. $^{28}$

\section{Measurement of direct medicine treatment cost}

Direct medicine treatment cost of AEDs was calculated by summing the medical scheme contribution and patient co-payment associated with each AED. The direct cost of oversupply was calculated by multiplying the average direct medicine cost per day with the total number of days supplied, subtracting the number of days the patient was supposed to receive the medication. Opportunity cost (cost of undersupply) was determined by calculating the average direct medicine cost per day with the number of days the patient was supposed to have received the medication, subtracting the total number of days supplied. Medicine cost was calculated in South African rand and converted to US dollars (average conversion rate 2008-2013: 0.1238). ${ }^{43}$

\section{Study variables}

Variables (age, sex, treatment period, active ingredients, and other comorbidities) were expressed using frequencies, percentages, mean, standard deviation (SD), and 95\% confidence interval (CI).

Patient age was calculated at the date of the first dispensing on the database in relation to his/her date of birth, and was used to categorize patients into five age groups: $0 \leq 12$ years, $>12$ to $\leq 18$ years, $>18$ to $\leq 40$ years, $>40$ to $\leq 65$ years, and $>65$ years and older.

Treatment duration was calculated as the days from the first prescription for AEDs up to the date of the last prescription, and divided into three groups: $\leq 30$ days; $>30$ to $\leq 120$ days, and $>120$ days. The treatment period can be described as the number of days the patient was supposed to receive medication.

The comorbid conditions were considered to be those chronic conditions registered on the South African PMB CDL. By definition, the PMB CDL, as a feature of the Medical Schemes Act 131 of 1998, is a regulated compilation of 25 conditions requiring treatment for over 12 months that are most common to the country, are considered to be life-threatening, and conditions where cost-effective treatment will sustain and improve the quality of the member's life. Medical aid schemes are obliged to cover the costs related to the diagnosis, treatment, and ongoing care of these conditions, to the extent that this is provided for by way of a therapeutic algorithm for the specified condition..$^{44,45}$ The CDL conditions were identified based on the presence of the following ICD-10 codes on claims reimbursed from patients' PMB benefits: Addison's disease (ICD-10 code E27.1), asthma (J45, J45.8), bronchiectasis (J47, Q33.4), cardiac failure (I50, I50.0, I50.1), cardiomyopathy (I42, I42.0, I25.5), chronic obstructive pulmonary disease (J43, $\mathrm{J} 44)$, chronic renal disease ( $\mathrm{N} 03, \mathrm{~N} 11, \mathrm{~N} 18)$, coronary artery disease (I20, I20.0, I25), Crohn's disease (K50, K50.8), diabetes insipidus (E23.2), diabetes mellitus type 1 and 2 (E11.0-E11.9), dysrhythmias (I47, I47.2, I48), epilepsy (G40, G40.8), glaucoma (H40, Q15.0), hemophilia (D66, D67), 
dyslipidemia (E78.0-E78.5), hypertension (I10.0, I11.0, I12.0, I13.0, I15.0), hypothyroidism (E02, E03, E03.8), multiple sclerosis (G35), Parkinson's disease (G20, G21), rheumatoid arthritis (M05, M06, M08.0), schizophrenia (F20), systemic lupus erythematous (M32, L93, L93.2), and ulcerative colitis (K51, K51.9).

\section{Statistical analysis}

Data management and analysis were performed by the SAS program version $9.3^{\circledR}$ (SAS Institute Inc., Cary, NC, USA). A probability of $P<0.0001$ was considered statistically significant. The practical significance of the results was computed when the $P$-value was statistically significant.

The chi-square test was used to compare the statistically significant associations between two categorical variables. Cramer's $V$ value was used to test the strength for any association or practical significance from the chi-square analysis. It could be interpreted as follows: effect size of 0.1 is small, effect size of 0.3 is medium, and an effect size of 0.5 is large. ${ }^{46}$

\section{Results}

Table 1 displays the basic characteristics of the study population. The mean age of the 19,168 patients in the study population was 45.61 ( $\mathrm{SD}=21.96)$ years, with more than half of these patients being women (Table 1).

Of the total 47,407 AEDs claimed during the study period (Table 2), only 55.14\% were associated with an acceptable MPRm. A further $30.58 \%$ of AEDs had an unacceptably low MPRm, whereas $14.27 \%$ had an unacceptably high MPRm. A chi-square test of independence was furthermore performed to examine the association between MPRm categories and age, sex, active ingredient prescribed, treatment period, number of comorbidities, and direct AED cost. Based on this

Table I Patient demographics

\begin{tabular}{ll}
\hline Variables & $\mathbf{N}(\%)$ \\
\hline $\begin{array}{l}\text { Total number of patients } \\
\text { Age (years) }\end{array}$ & 19,168 \\
Mean (SD) & $45.61(21.96)$ \\
Age groups (years) & \\
0 to $\leq 12$ & $1,411(7.36)$ \\
$>12$ to $\leq 18$ & $1,163(6.07)$ \\
$>18$ to $\leq 40$ & $5,067(26.43)$ \\
$>40$ to $\leq 65$ & $7,424(38.73)$ \\
$>65$ & $4,103(21.4 I)$ \\
Sex & \\
Male & $8,852(46.18)$ \\
Female & $10,316(53.82)$ \\
\hline
\end{tabular}

Note: All values are presented as frequencies and percentages, except where stated otherwise.

Abbreviation: SD, standard deviation. analysis, the relationship between MPRm categories and sex was independent $(P<0.018$; Cramer's $V=0.009)$, whereas the relationship between $\mathrm{MPRm}$ categories and age was statistically but not practically significant $(P<0.0001$; Cramer's $V=0.067$ ). Analysis within the acceptable MPRm category, however, showed that the percentage of AEDs increased by age from $46.41 \%$ in patients aged 0 to $\leq 12$ years to $61.50 \%$ $(\mathrm{N}=26,142)$ in those aged $>65$ years.

The top ten most dispensed active ingredients $(\mathrm{N}=43,133)$ accounted for $90.98 \%$ of all AEDs (Table 2). These included valproate $(22.55 \%)$, lamotrigine $(21.96 \%)$, carbamazepine (15.62\%), topiramate $(8.21 \%)$, phenytoin $(8.05 \%)$, clonazepam (5.33\%), levetiracetam (3.79\%), gabapentin (2.27\%), valproic acid $(2.25 \%)$, and oxcarbazepine (0.96\%). A statistically significant association was observed between the type of active ingredient and MPRm categories; however, this association was not practically significant (Cramer's $V=0.071$ ) (Table 2). Analysis within each active ingredient group showed that the AED with the highest acceptable MPRm was oxcarbazepine (64.5\%), followed by valproic acid $(63.7 \%)$ and phenytoin (58.7\%). The AEDs with the highest unacceptably low MPRm included gabapentin $(38.07 \%, \mathrm{~N}=1,077)$ and clonazepam (32.87\%, N=2,528), whereas levetiracetam (19.55\%, $\mathrm{N}=1,795)$ and topirimate $(16.32 \%, \mathrm{~N}=3,892)$ had the highest unacceptably high MPRm (Table 2).

Treatment period was statistically and practically significantly associated with MPRm categories $(P>0.0001$; Cramer's $V=0.208)$. AEDs prescribed for longer than 120 days were more likely to be associated with an acceptable MPRm than were AEDs prescribed for less than 30 days (Table 2).

In the majority of cases where AEDs $(58.41 \%, \mathrm{~N}=47,407)$ were prescribed, the patients did not present with other comorbidities. Furthermore, the number of comorbid conditions were statistically but not practically significantly associated with MPRm categories ( $P \leq 0.0001$; Cramer's $V=0.05$ ) (Table 2).

Table 3 shows the direct AED cost associated with the different MPRm categories. Medical aid schemes contributed $75.97 \%$ (US\$14,972,164.61) toward the cost over the study period. AEDs with an unacceptably high MPRm amounted to US\$736,376.23 (3.74\%) of the total cost of AEDs over the 6 -year period. One-third of AEDs had an unacceptably low MPRm, representing an opportunity cost of US\$3,227,894.85 (16.38\%) (Table 3).

\section{Discussion}

Nonadherence in patients taking AEDs is a major concern, not only in developed countries but also in middle-income 
Table 2 Modified medicine possession ratio (MPRm) for antiepileptic drugs

\begin{tabular}{|c|c|c|c|c|c|c|}
\hline \multirow[t]{2}{*}{ Variables } & \multirow[t]{2}{*}{$\mathbf{N}$} & \multicolumn{3}{|l|}{ MPRm category } & \multirow[t]{2}{*}{$P$-value } & \multirow[t]{2}{*}{ Cramer's V } \\
\hline & & $\begin{array}{l}\geq \mathbf{8 0} \% \text { to } \leq \mathrm{II} 0 \%^{\mathrm{a}} \\
\mathrm{n}(\%)\end{array}$ & $\begin{array}{l}<\mathbf{8 0} \%^{\mathrm{b}} \\
\mathrm{n}(\%)\end{array}$ & $\begin{array}{l}>110 \% c \\
\text { n (\%) }\end{array}$ & & \\
\hline Overall active ingredients & 47,407 & $26,142(55.14)$ & 14,498 (30.58) & $6,767(14.27)$ & & \\
\hline Age group (years) & & & & & $<0.0001$ & 0.067 \\
\hline 0 to $\leq 12$ & 2,812 & I,305 (4.99) & $\mathrm{I}, 142(7.88)$ & 365 (5.39) & & \\
\hline$>12$ to $\leq 18$ & 2,762 & I,367 (5.23) & $\mathrm{I}, 034(7.13)$ & 361 (5.33) & & \\
\hline$>18$ to $\leq 40$ & $|3,57|$ & $7,07 \mid(27.05)$ & $4,430(30.56)$ & $2,070(30.59)$ & & \\
\hline$>40$ to $\leq 65$ & 18,760 & $10,555(40.38)$ & $5,496(37.91)$ & $2,709(40.03)$ & & \\
\hline$>65$ & 9,502 & $5,844(22.35)$ & $2,396(16.53)$ & $1,262(18.65)$ & & \\
\hline Sex, n (\%) & & & & & 0.182 & 0.009 \\
\hline Male & 21,138 & II,752 (44.95) & $6,416(44.25)$ & $2,970(43.89)$ & & \\
\hline Female & 26,269 & $14,390(55.05)$ & $8,082(55.75)$ & $3,797(56.11)$ & & \\
\hline Top ten active ingredients & & & & & $<0.0001$ & $0.07 \mid$ \\
\hline Valproate & 10,690 & $5,931(22.69)$ & $3,329(22.96)$ & I,430 (2I.I3) & & \\
\hline Lamotrigine & $|0,4| \mid$ & $5,748(21.99)$ & $3,268(22.54)$ & I,395 (20.6I) & & \\
\hline Carbamazepine & 7,404 & 4,158 (I5.9I) & $2,203(15.20)$ & $\mathrm{I}, 043(15.4 \mathrm{I})$ & & \\
\hline Topirimate & 3,892 & $2,006(7.67)$ & $\mathrm{I}, 25 \mathrm{I}(8.63)$ & $635(9.38)$ & & \\
\hline Phenytoin & $3,8 \mid 4$ & $2,240(8.57)$ & $\mathrm{I}, 060(7.3 \mathrm{I})$ & $5 / 4(7.60)$ & & \\
\hline Clonazepam & 2,528 & I,355 (5.18) & 831 (5.73) & $342(5.05)$ & & \\
\hline Levetiracetam & $\mathrm{I}, 795$ & $977(3.74)$ & $467(3.22)$ & $351(5.19)$ & & \\
\hline Gabapentin & $\mathrm{I}, 077$ & $492(1.88)$ & $410(2.83)$ & 175 (2.59) & & \\
\hline Valproic acid & 1,066 & $679(2.60)$ & $273(1.88)$ & $114(1.68)$ & & \\
\hline Oxcarbazepine & 456 & $294(I .12)$ & $102(0.70)$ & $60(0.89)$ & & \\
\hline Treatment period (days) & & & & & $<0.0001$ & 0.208 \\
\hline$\leq 30$ & 2,587 & $986(3.77)$ & $210(1.45)$ & I,39I (20.56) & & \\
\hline$>30$ to $\leq 120$ & 8,750 & $4,336(16.59)$ & $2,71 I(18.70)$ & I,703 (25.17) & & \\
\hline$>120$ & 36,070 & $20,820(79.64)$ & I I,577 (79.85) & $3,673(54.28)$ & & \\
\hline Number of comorbidities & & & & & $<0.0001$ & 0.050 \\
\hline No comorbidities & 27,692 & $\mid 4,752(56.43)$ & $9,155(63.15)$ & 3,785 (55.93) & & \\
\hline I & 10,736 & $6,252(23.92)$ & $2,962(20.43)$ & I,522 (22.49) & & \\
\hline 2 & 5,508 & $3,220(12.32)$ & $\mathrm{I}, 427(9.84)$ & 861 (12.72) & & \\
\hline 3 & 2,469 & I,365 (5.22) & $696(4.80)$ & $408(6.03)$ & & \\
\hline 4 & 783 & $444(1.70)$ & $188(1.30)$ & $15 \mid(2.23)$ & & \\
\hline 5 & 184 & $88(0.34)$ & $63(0.43)$ & $33(0.49)$ & & \\
\hline$\geq 6$ & 32 & $18(0.07)$ & $7(0.05)$ & $7(0.10)$ & & \\
\hline
\end{tabular}

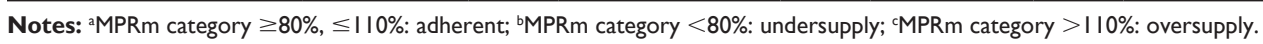

countries such as South Africa. Although the 55.14\% adherence rate described in this study was in range with findings from studies conducted on medical care claims databases ${ }^{13,15,30-34}$ and studies conducted in the public health sector of South Africa (eg, $54.6 \%$ and $42.9 \%$, respectively), it is still relatively poor compared to the advocated $80 \%{ }^{25,42}$ These findings underscore the importance of assessing adherence to AEDs in the South African health sector.
According to Garnett, ${ }^{49}$ there are generally three types of factors that may influence medication adherence to AEDs in particular: 1) patient-related factors such as forgetfulness and stigmatization; 2) medication-related factors such as cost, side effects, number of medications prescribed, and dosing frequency; and 3) disease-related factors including seizure type and severity and duration of illness. Other factors that may also influence adherence to AEDs include not having

Table 3 Direct medicine cost associated with MPRm categories

\begin{tabular}{|c|c|c|c|c|}
\hline & \multirow[t]{2}{*}{$\mathbf{N}$} & \multicolumn{3}{|l|}{ MPRm category } \\
\hline & & $\begin{array}{l}\geq 80 \% \text { to } \leq I 10 \%^{a} \\
\text { n (\%) }\end{array}$ & $\begin{array}{l}<\mathbf{8 0} \%^{\mathrm{b}} \\
\text { n (\%) }\end{array}$ & $\begin{array}{l}>110 \% c \\
\text { n (\%) }\end{array}$ \\
\hline Number of items & 47,407 & $26,142(55.14)$ & $14,498(30.58)$ & $6,767(14.27)$ \\
\hline Total cost (US\$) & $|9,707,905.3|$ & I 5,743,643.24 & $3,227,894.85$ & $736,376.23$ \\
\hline Medical scheme contribution (US\$) & $|4,972| 64.6 \mid$, & I2,480, I 57.30 (79.27) & $2,486,430.34(77.02)$ & $5,576.98(0.76)$ \\
\hline Patient contribution (US\$) & $4,735,740.70$ & $3,263,476.94(20.73)$ & $74 I, 464.5 \mathrm{I}(22.97)$ & $730,799.25$ (99.24) \\
\hline
\end{tabular}

Notes: aMPRm category $\geq 80 \%, \leq 110 \%$ : adherent; bMPRm category $<80 \%$ : undersupply; cMPRm category $>$ I I0\%: oversupply. 
enough medication on hand, ${ }^{18}$ poor understanding and low health literary, ${ }^{50,51}$ impairment (eg, poor eye sight), ${ }^{50}$ lack of counseling and/or communication skills, time and appropriate knowledge among health care workers, ${ }^{48}$ changes to a new regime or a new formulation, ${ }^{52}$ and socioeconomic status. ${ }^{53}$ In this study, we identified a longer treatment period as potential predictor of adherence to AEDs, similar to several other studies. ${ }^{31,34,54}$ According to Sweileh et al, ${ }^{31}$ this may be due to the patients' realization of the benefits of adherence through time, or because they are willing to tolerate side effects of AEDs and adhere to their medication regimens as long as they are satisfied with the effectiveness of these regimens.

In our study, the relation between adherence status and age was statistically but not practically significant. The available literature is conflicting in its findings with regard to the association between age and adherence to AEDs, with some studies showing that younger patients were less adherent with AEDs, ${ }^{55,56}$ whereas others suggested otherwise, ${ }^{31,32}$ or no association. ${ }^{57,58}$ Explanations raised for these findings included that older patients may realize the importance and benefits of adherence and therefore be more adherent. ${ }^{31,32}$ On the other hand, studies that have shown that adherence decreases with increasing age ${ }^{59,60}$ indicated cost, medical insurance, or forgetfulness as main reasons for nonadherence. According to Cooper et al, ${ }^{61}$ however, age by itself is not the determining factor in medication nonadherence. Many factors may combine to render a person less able to adhere to their medication regimens; these include the specific illness, the treatment time frame, medication regimen, and the cognitive/ affective status of the patient.

AED adherence was independent of sex in the present study. Women are generally less likely than men to be adherent in their use of chronic medications ${ }^{60,62}$ and to receive medication treatment and monitoring recommended by clinical guidelines. ${ }^{62}$ According to Harden et al, ${ }^{63}$ this may be ascribed to the stigma associated with epilepsy; however, this usually depends on the patient's situation and attitude. ${ }^{64}$

Similar to findings by Baker et $\mathrm{al}^{65}$ and Zeber et al, ${ }^{66}$ the top three active ingredients that represented the highest adherence rate were oxcarbazepine, valproic acid, and phenytoin. These AEDs are given as first-line treatment, have available generics and the extended release forms ${ }^{67}$ that make once-a-day dosing possible, ${ }^{68,69}$ which may be the reason for the high adherence rates observed in our study. Gabapentin and clonazepam, on the other hand, were more likely to be undersupplied, and topirimate and levetiracetam oversupplied, supporting results by Zeber et al showing that gapapentin use may significantly less likely to be adherent, whereas levetiracetam was positively associated with adherence. Drugs that cause cognitive difficulty or weight gain normally affect adherence, particularly if the patient has not been on treatment for long periods. ${ }^{66}$ Weight gain and cognitive difficulty are commonly associated with the mood stabilizers such as valproic acid (sodium valproate) and to a lesser extent with carbamazepine, and some of the newer anticonvulsants such as vigabatrin and gabapentin. ${ }^{70}$

Only $\sim 40 \%$ of patients from our study population receiving AEDs presented with other comorbidities. There was also no practically significant association between the number of comorbidities and adherence as measured using the MPRm. Current literature studies report conflicting results, with some of these studies reporting a lower adherence with multiple comorbid conditions, ${ }^{60,71,72}$ whereas others indicated a better adherence rate as the number of coexisting conditions increased. ${ }^{30}$ Reasons cited for a lower adherence rate in patients with coexisting conditions include that they may require complex treatment regimens. As treatment complexity increases, patients' understanding of the treatment regimen may decrease, leading to failure to take medications as prescribed. ${ }^{73}$ Treatment complexity may also interfere with symptom control. ${ }^{56}$

Nonadherence to medication does not only have a negative impact on clinical outcomes, but also on the economic consequences. Undersupply of medication contributed to $16.38 \%$ of the total direct costs associated with AEDs in our study. These patients who were undersupplied in terms of medicine $(30.58 \%)$ possibly did not receive adequate treatment and did not reach optimal therapeutic effect. On the other hand, oversupply of medication contributed to $3.74 \%$ of the total direct costs associated with AEDs on the database over the study period. Nonadherence to antiepileptic treatment therefore encompassed $\sim 20 \%$ of cost in our study. South Africa spent $\sim 8.9 \%$ of its Gross Domestic Product on health sector financing in 2013, way more than the $5 \%$ recommended by the World Health Organization. ${ }^{74}$ One of the primary cost drivers of medical expenditure in the private health sector during this time has been medicines, accounting for $15.8 \%$ of the total spent by medical aid schemes during the 2012/2013 financial year. Other main contributors to medical scheme costs were hospitals and specialists, accounting for $36.4 \%$ and $23.3 \%$ of expenditure, respectively. ${ }^{75}$ This underscores the importance of assessing prescription refill adherence to AEDs in the South African health sector, enabling prompt response to potential health concerns and avoiding unnecessary costs. 
Finally, our study adds to the limited literature on nonadherence to AEDs and associated cost implications in epilepsy patients in the private health sector of South Africa. The MPRm, albeit based on the assumption that patients take all medications for which they have prescriptions filled, allows for evaluation of adherence levels using pharmaceutical claims data. Limitations that should be considered when interpreting the results include that patients may also have acquired prescription medications from sources other than the pharmacies included in the database, or paid out-of-pocket for medicines, in which case the prevalence of nonadherence may be overestimated. The number of comorbidities investigated in the epileptic patients was a special group of diagnoses covered by the $\mathrm{CDL}$ in the PMB. These conditions were chosen due to the fact that they are covered by medical aid schemes (doctor's consultations, tests related to condition and medication cover), even if a member's benefits for the year have run out. The prevalence of comorbidities and their influence on adherence could therefore also be underestimated. Because we analyzed pharmaceutical claims data, we could not assess the pertinent reasons for patient's prescription refill adherence in our study.

\section{Conclusion}

We showed that the adherence with AEDs for epileptic patients in the South African private health sector as determined on the claims database was relatively poor. We furthermore established that the poor adherence with AED treatment contributed significantly to an added cost in the treatment of epilepsy in a middle-income country such as South Africa.

The responsibility for adherence must be shared by health professionals, the health care system, the community, and patients. ${ }^{9}$ Awareness should therefore be created among health professionals with regard to current prescribing patterns of AEDs, the level of nonadherence, and the subsequent cost implications thereof. Further studies to determine the factors influencing epileptic patients' prescription refill adherence would be a logical next step in this field of research.

\section{Acknowledgments}

We thank Ms Anne-Marie Bekker for administrative support regarding the database.

\section{Disclosure}

The authors report no conflicts of interest in this work.

\section{References}

1. WHO (World Health Organization). Epilepsy. Geneva: World Health Organization; 2015. Available from: http://www.who.int/mediacentre/ factsheets/fs 999/en/index.html. Accessed August 19, 2015.

2. Christainson AL, Zwane ME, Manga P, Rosen E, Venter A, Kromberg JG. Epilepsy in rural South African children: prevalence, associated disability and management. S Afr Med J. 2000;90(3):262-266.

3. Wagner RG, Ngugi AK, Twine R, et al. Prevalence and risk factors for active convulsive epilepsy in rural northeast South Africa. Epilepsy Res. 2014;108(4):782-791.

4. Birbeck GL, Hays RD, Cui X, Vickrey BG. Seizure reduction and quality of life improvements in people with epilepsy. Epilepsia. 2002; 43(5):535-538.

5. Tiamkao S, Kaewkiow N, Pranbul S; for Integrated Epilepsy Research Group. Validation of a seizure-related injury model. J Neurol Sci. 2014;336(1-2):113-115.

6. Nei M, Bagla R. Seizure-related injury and death. Curr Neurol Neurosci Rep. 2007;7(4):335-341.

7. Bellon M, Walker C, Peterson C. Seizure-related injuries and hospitalizations: self-report data from the 2010 Australian Epilepsy Longitudinal Survey. Epilepsy Behav. 2013;26(1):7-10.

8. Camfield C, Camfield P. Injuries from seizures are a serious, persistent problem in childhood onset epilepsy: a population-based study. Seizure. 2015;27:80-83.

9. Sabaté E, ed. Adherence to Long-term Therapies: Evidence for Action. Geneva: World Health Organization; 2003.

10. Vrijens B, De Geest S, Hughes DA; for ABC Project Team. A new taxonomy for describing and defining adherence to medications. Br J Clin Pharmacol. 2012;73(5):691-705.

11. Hugtenburg JG, Timmers L, Elders PJ, Vervloet M, van Dijk L. Definitions, variants, and causes of nonadherence with medication: a challenge for tailored interventions. Patient Prefer Adherence. 2013;(7): 675-682.

12. Hedna K, Hägg S, Andersson Sundell K, Petzold M, Hakkarainen KM. Refill adherence and self-reported adverse drug reactions and subtherapeutic effects: a population-based study. Pharmacoepidemiol Drug Saf. 2013;22(12):1317-1325.

13. Hovinga CA, Asato MR, Manjunath R, et al. Association of nonadherence to antiepileptic drugs and seizures, quality of life, and productivity: survey of patients with epilepsy and physicians. Epilepsy Behav. 2008;13(2):316-322.

14. Jones RM, Butler JA, Thomas VA, Peveler RC, Prevett M. Adherence to treatment in patients with epilepsy: associations with seizure control and illness beliefs. Seizure. 2006;15(7):504-508.

15. Cramer JA, Glassman MG, Rienzi V. The relationship between poor medication compliance and seizures. Epilepsy Behav. 2002;3(4):338-342.

16. Samsonsen C, Reimers A, Bråthen G, Helde G, Brodtkorb E. Nonadherence to treatment causing acute hospitalizations in people with epilepsy: an observational, prospective study. Epilepsia. 2014;55(11):e125-e128

17. Ladner TR, Morgan CD, Pomerantz DJ, et al. Does adherence to epilepsy quality measures correlate with reduced epilepsy-related adverse hospitalization: a retrospective experience. Epilepsia. 2015;56(5): e63-e67.

18. Manjunath R, Davis KL, Candrilli SD, Ettinger AB. Association of antiepileptic drug nonadherence with risk of seizures in adults with epilepsy. Epilepsy Behav. 2009;14(2):372-378.

19. Sander JW, Bell GS. Reducing mortality: an important aim of epilepsy management. J Neurol Neurosurg Psychiatr. 2004;75(3):349-351.

20. Faught E, Duh MS, Weiner JR, Guérin A, Cunnington MC. Nonadherence to antiepileptic drugs and increased mortality: findings from the RANSOM study. Neurology. 2008;71(20):1572-1578.

21. Frediani F, Cannatà AP, Magnoni A, Peccarisi C, Bussone G. The patient with medication overuse: clinical management problems. Neurol Sci. 2003;24(Suppl 2):s108-s111.

22. Stroupe KT, Murray MD, Stump TE, Callahan CM. Association between medication supplies and healthcare costs in older adults from an urban healthcare system. $J$ Am Geriatr Soc. 2000;48(7):760-768. 
23. Kingsman K, Melander A, Carlsten A, Ekedahl A, Nilsson JL. Refill non-adherence to repeat prescriptions leads to treatment gaps or to high extra costs. Pharm World Sci. 2007;29(1):19-24.

24. Davis KL, Candrilli SD, Edin HM. Prevalence and cost of nonadherence with antiepileptic drugs in an adult managed care population. Epilepsia. 2008;49(3):446-454.

25. Ettinger AB, Manjunath R, Candrilli SD, Davis KL. Prevalence and cost of non-adherence to anti-epileptic drugs in elderly patients with epilepsy. Epilepsy Behav. 2009;14(2):324-329.

26. Iuga AO, McGuire MJ. Adherence and health care costs. Risk Manag Healthc Policy. 2014;7:35-44.

27. Faught RE, Weiner JR, Guérin A, Cunnington MC, Duh MS. Impact of nonadherence to antiepileptic drugs on health care utilization and costs: findings from the RANSOM study. Epilepsia. 2009;50(3):501-509.

28. YHEC/School of Pharmacy, University of London; 2010. Evaluation of the Scale, Causes and Costs of Waste Medicines. Available from: http://discovery.ucl.ac.uk/1350234/1/Evaluation_of_NHS_Medicines_ Waste_web_publication_version.pdf. Accessed January 10, 2016.

29. Chen CC, Blank RH, Cheng SH. Medication supply, healthcare outcomes and healthcare expenses: longitudinal analysis of patients with type 2 diabetes and hypertension. Health policy. 2014;117(3):374-381.

30. Briesacher BA, Andrade SE, Fouayzi H, Chan KA. Comparison of drug adherence rates among patients with seven different medical conditions. Pharmacotherapy. 2008;28(4):437-443.

31. Sweileh WM, Ihbesheh MS, Jarar IS, et al. Self-reported medication adherence and treatment satisfaction in patients with epilepsy. Epilepsy Behav. 2011;21(3):301-305.

32. Lusić I, Titlić M, Eterović D. Epileptic patient compliance with prescribed medical treatment [abstract]. Acta Med Croatica. 2005;59(1): 13-18.

33. Asawavichienjinda T, Sitthi-Amorn C, Tanyanont W. Compliance with treatment of adult epileptics in a rural district of Thailand. J Med Assoc Thai. 2003;86(1):46-51.

34. Hodges JC, Treadwell J, Malphrus AD, Tran XG, Giardino AP. Identification and prevention of antiepileptic drug noncompliance: the collaborative use of state-supplied pharmaceutical data. ISRN Pediatr. 2014;2014:734689.

35. Mantri P. Medication adherence in adults with epilepsy. Pract Nurs. 2015;26(4):179-184.

36. Andrade SE, Kahler KH, Frech F, Chan KA. Methods for evaluation of medication adherence and persistence using automated databases. Pharmacoepidemiol Drug Saf. 2006;15(8):565-574.

37. Marcum ZA, Gurwitz JH, Colón-Emeric C, Hanlon JT. Pills and ills: methodologic issues in pharmacologic research. J Am Geriatr Soc. 2015;63(4):829-830.

38. Park H, Rascati KL, Lawson KA, Barner JC, Richards KM, Malone DC. Adherence and persistence to prescribed medication therapy among Medicare part D beneficiaries on dialysis: comparisons of benefit type and benefit phases. J Manag Care Spec Pharm. 2014;20(8):862-876.

39. Thier SL, Yu-Isenberg KS, Leas BE, et al. In chronic disease, nationwide data show poor adherence by patients to medication and by physicians to guidelines. Manag Care. 2008;17(2):48-57.

40. Karve S, Cleves MA, Helm M, Hudson TJ, West DS, Martin BC. Prospective validation of eight different adherence measures for use with administrative claims data among patients with schizophrenia. Value Health. 2009;12(6):989-995.

41. Sikka R, Xia F, Aubert RE. Estimating medication persistency using administrative claims data. Am J Manag Care. 2005;11(7):449-457.

42. Osterberg L, Blaschke T. Adherence to medication. N Engl J Med. 2005; 353(5):487-497.

43. OANDA Corporation; c1996-c2015. Currency converter. Available from: http://www.oanda.com/currency/converter/. Accessed August 27, 2015.

44. Council for Medical Schemes, South Africa; 2010. Prescribed minimum benefits (PMB's) aim to provide you with continuous care. Available from: http://www.medicalschemes.com/ReadNews.aspx?2. Accessed February 01, 2015.
45. Council for Medical Schemes, South Africa; 1998. Medical Schemes Act, 131 of 1998. Available from: https://www.medicalschemes.com/ Content.aspx?130. Accessed February 01, 2015.

46. Ellis SM, Steyn HS. Practical significance (effect sizes) versus or in combination with statistical significance (p-values). Manag Dynam. 2003;12(4):51-53.

47. Egenasia C, Steinberga WJ, Raubenheimer JE. Beliefs about medication, medication adherence and seizure control among adult epilepsy patients in Kimberley, South Africa. SA Fam Pract. 2015;57(5):326-332.

48. Krause SR, Van Rooyen FC, Van Vuuren MVJ, Jenkins L. Noncompliance with treatment by epileptic patients at George Provincial Hospital. SA Fam Pract. 2007;49(9):14a-14d.

49. Garnett WR. Antiepileptic drug treatment: outcomes and adherence. Pharmacotherapy. 2000;20(8 Pt 2):191S-199S.

50. Mbuba CK, Ngugu AK, Fegan G, et al. Risk factors associated with the epilepsy treatment gap in Kilifi, Kenya: a cross-sectional study. Lancet Neurol. 2011;11(8):688-696.

51. Keikelame MJ, Swartz L. Lost opportunities to improve health literacy: observations in a chronic illness clinic providing care for patients with epilepsy in Cape Town South Africa. Epilepsy Behav. 2013;26(1): 36-41.

52. Buck D, Jacoby A, Baker GA, Chadwick DW. Factors influencing compliance with antiepileptic drug regimes. Seizure. 1997;6(2):87-93.

53. Paschal AM, Rush SE, Sadler T. Factors associated with medication adherence in patients with epilepsy and recommendations for improvement. Epilepsy Behav. 2014;31:346-350.

54. Shetty J, Kirkpatrick M, Greene S. Adherence to anti-epileptic medication in children with epilepsy from a Scottish population cohort. Arch Dis Child. 2012;97(Suppl 1):A135.

55. Tan XC, Makmor-Bakry M, Lau CL, Tajarudin FW, Raymond AA. Factors affecting adherence to antiepileptic drugs therapy in Malaysia. Neurol Asia. 2015;20(3):235-241.

56. Ferrari CMM, de Sousa RM, Castro LHM. Factors associated with treatment non-adherence in patients with epilepsy in Brazil. Seizure. 2013;22(5):384-389.

57. Gurumurthy R, Chanda K, Sarma G. An evaluation of factors affecting adherence to anti-epileptic drugs in patients with epilepsy: a crosssectional study. Singapore Med J. Epub 2016 Jan 25.

58. Gabr WM, Shams ME. Adherence to medication among outpatient adolescents with epilepsy. Saudi Pharm J. 2015;23(1):33-40.

59. Bautista RED, Rundle-Gonzalez V. Effects of antiepileptic drug characteristics on medication adherence. Epilepsy Behav. 2012;23(4): 437-441.

60. Rolnick SJ, Pawloski PA, Hedblom BD, Asche SE, Bruzek RJ. Patient characteristics associated with medication adherence. Clin Med Res. 2013;11(2):54-65.

61. Cooper JK, Love DW, Raffoul PR. Intentional prescription nonadherence (noncompliance) by the elderly. J Am Geriatr Soc. 1982;30(5): 329-333.

62. Manteuffel M, Williams S, Chen W, Verbrugge RR, Pittman DG, Steinkellner A. Influence of patient sex and gender on medication use, adherence, and prescribing alignment with guidelines. $J$ Womens Health (Larchmt). 2014;23(2):112-119.

63. Harden C, Thomas SV, Tomson T, eds. Epilepsy in Women. Oxford: John Wiley \& Sons; 2013.

64. Ahmed R, Aslani P. Impact of gender on adherence to therapy. J Malta College Pharm Pract. 2014;(20):21-23.

65. Baker GA, Jacoby A, Buck D, Stalgis C, Monnet D. Quality of life of people with epilepsy: a European study. Epilepsia. 1997;38(3):353-362.

66. Zeber JE, Copeland LA, Pugh MJ. Variation in antiepileptic drug adherence among older patients with new-onset epilepsy. Ann Pharmacother. 2010;44(12):1896-1904.

67. Perucca E, Tomson T. The pharmacological treatment of epilepsy in adults. Lancet Neurol. 2011;10(5):446-456.

68. Uthman BM. Extended-release antiepilepsy drugs: review of the effects of once-daily dosing on tolerability, effectiveness, adherence, quality of life, and patient preference. US Neurol. 2014;10(1):30-37. 
69. Council for Medical Schemes, South Africa. Medical Schemes Act, 1998 (Act no. 131 of 1998). Regulations made in terms of the Medical Scheme Act, 1998 therapeutic algorithms for chronic conditions. (Notice 1402). Government Gazette. 2003;25537:53-111.

70. Jallon P, Picard F. Bodyweight gain and anticonvulsants: a comparative review. Drug Saf. 2001;24(13):969-978.

71. Marcum ZA, Gellad WF. Medication adherence to multi-drug regimens. Clin Geriatr Med. 2012;28(2):287-300.

72. Saadat Z, Nikdoust F, Aerab-Sheibani H, et al. Adherence to antihypertensives in patients with comorbid condition. Nephrourol Mon. $2015 ; 7(4): 1-6$
73. McAuley JW, McFadden LS, Elliott JO, Shneker BF. An evaluation of self-management behaviors and medication adherence in patients with epilepsy. Epilepsy Behav. 2008;13(4):637-641.

74. WHO (World Health Organization). 2016. Global Health Expenditure Database. Available from: http://apps.who.int/nha/database/ViewData/ Indicators/en. Accessed January 28, 2016.

75. Council for Medical Schemes, South Africa. 2013. Available from: https://www.medicalschemes.com/files/Annual\%20Reports/ f0868c30e186Z.html. Accessed January 28, 2016.

\section{Publish your work in this journal}

Patient Preference and Adherence is an international, peer-reviewed, open access journal that focuses on the growing importance of patient preference and adherence throughout the therapeutic continuum. Patient satisfaction, acceptability, quality of life, compliance, persistence and their role in developing new therapeutic modalities and compounds to optimize clinical outcomes for existing disease states are major areas of interest for the journal. This journal has been accepted for indexing on PubMed Central. The manuscript management system is completely online and includes a very quick and fair peer-review system, which is all easy to use. Visit http://www. dovepress.com/testimonials.php to read real quotes from published authors.

\footnotetext{
Submit your manuscript here: http://www.dovepress.com/patient-preference-and-adherence-journal
} 